\title{
AS PAIXÕES, AS PULSÕES E AS EMOÇÕES HUMANAS EM ARISTÓTELES, FREUD E NORBERT ELIAS: UMA REFLEXÃO PARA A EDUCAÇÃO CONTEMPORÂNEA
}

\author{
THE PASSIONS, THE INSTINCTS ${ }^{1}$ AND THE HUMAN \\ EMOTIONS IN ARISTOTLE, FREUD AND NORBERT ELIAS: \\ A REFLECTION FOR CONTEMPORARY EDUCATION
}

\section{LAS PASIONES, LAS PULSONES Y LAS EMOCIONES HUMANAS EN ARISTÓTELES, FREUD Y NORBERT ELÍAS: UNA REFLEXIÓN PARA LA EDUCACIÓN CONTEMPORÁNEA}

\author{
Alonso Bezerra Carvalho Correio ${ }^{\mathrm{I}}$ \\ Carlos Fonseca Brandão Correio ${ }^{\mathrm{II}}$
}

\begin{abstract}
Resumo Este artigo visa refletir acerca do papel e da importância dos estados afetivos como as paixões, as pulsões e as emoções no processo de constituição, formação e ação dos indivíduos e da própria sociedade e suas possíveis ressonâncias na educação. De caráter teórico, parte da exposição de um problema crucial na vida escolar atualmente: a questão da violência. Em seguida, trata de expor a compreensão que Aristóteles, Freud e Norbert Elias tiveram a respeito desses estados afetivos, articulando-a com os desafios que são enfrentados por professores e alunos em uma sala de aula. As emoções, as paixões e as pulsões pertencem à natureza humana, isto é, para conhecer melhor os homens talvez devêssemos começar a observar como nós lidamos com elas, o que pode contribuir na compreensão do caráter de um indivíduo e de um grupo. Nesse aspecto, a melhor maneira de se estabelecer estratégias para influenciar a conduta de uma pessoa está em considerar esse outro lado da existência, o que pode explicar as atitudes violentas. Portanto, as contribuições da filosofia,
\end{abstract}

Ver a nota de rodapé número 3.

I Universidade Estadual Paulista - UNESP, São Paulo, SP, Brasil.

II Universidade Estadual Paulista - UNESP, São Paulo, SP, Brasil. 
da psicologia e da sociologia e tomando o ambiente escolar como um lugar formativo, onde se manifestam os mais diversos tipos de sentimentos, pode nos conduzir a um modo de vida pautado na moderação, na prudência e na temperança, isto é, em virtudes que garantam a experiência da felicidade, da tolerância e do respeito.

Palavras-chave: Paixões; Pulsões; Emoções; Ética; Formação Humana.

Abstract This article aims to reflect on the role and importance of affective states as the passions, the instincts and the emotions in the process of constitution, formation and action of individuals and society itself and its possible resonances in education. From theoretical character, comes from the exposition of a crucial problem in school life today: the issue of violence. Next, it tries to expose the understanding that Aristotle, Freud and Norbert Elias had about these affective states, articulating it with the challenges that are faced by teachers and students in a classroom. Emotions, passions and instincts belong to human nature, that is, to get to know men better, perhaps we should begin to observe how we deal with them, which can contribute to the understanding of the character of an individual and a group. In this respect, the best way to establish strategies for influencing a person's conduct is to consider this other side of existence, which may explain violent attitudes. Therefore, the contributions of philosophy, psychology and sociology, and taking the school environment as a formative place, where the most diverse kinds of feelings are manifested, can lead us to a way of life based on moderation, prudence and temperance, that is, virtues that guarantee the experience of happiness, tolerance and respect.

Key-words: Passions; Impulses; Emotions; Ethic; Human Formation.

Resumen Este artículo tiene por objeto reflexionar sobre el papel y la importancia de los estados afectivos como las pasiones, las pulsiones y las emociones en el proceso de constitución, formación y acción de los individuos y de la propia sociedad y sus posibles resonancias en la educación. De carácter teórico, parte de la exposición de un problema crucial en la vida escolar actualmente: la cuestión de la violencia. A continuación, trata de exponer la comprensión que Aristóteles, Freud y Norbert Elias tuvieron acerca de esos estados afectivos, articulándola con los desafíos que son enfrentados por profesores y alumnos en un aula. Las emociones, las pasiones y las pulsiones pertenecen a la naturaleza humana, es decir, para conocer mejor a los hombres tal vez deberíamos empezar a observar cómo manejamos con ellas, lo que puede contribuir en la comprensión del carácter de un individuo y de un grupo. En este aspecto, la mejor manera de establecer estrategias para influir en la conducta de una persona está en considerar ese otro lado de la existencia, lo que puede explicar las actitudes violentas. Por lo tanto, las contribuciones de la filosofía, de la psicología y de la sociología y tomando el ambiente escolar como un lugar formativo, donde se manifiestan los más diversos tipos de sentimientos, puede conducirnos a un modo de vida pautado en la moderación, la prudencia y la templanza, es decir, en virtudes que garanticen la experiencia de la felicidad, de la tolerancia y del respeto.

Palabras-clave: Pasiones; Pulsiones; Emociones; Ética; Formación Humana. 


\section{INTRODUÇÃo}

Ao iniciar a escrita deste texto, a motivação que nos faz prosseguir é produzir algumas reflexões que, mesmo teóricas, possam contribuir para se pensar e enfrentar algumas questões, problemas e desafios que movimentam e atingem diretamente o ambiente educacional. Ao ser lido, esperamos que ele faça sentido e responda a alguns anseios e dramas que os educadores lidam na escola, especialmente na sala de aula. Falar de formação humana a partir de noções como as emoções, paixões e pulsões é pouco usual e ainda provido de desconfianças e receios por parte de pesquisadores, mas sobretudo, por parte daqueles que estão no front do processo de ensino e aprendizagem. Ao predominar uma concepção e uma atitude que valorizam a razão, a ciência e os saberes epistemologicamente fundamentados, resta um espaço pequeno para dimensões e elementos que nos constituem e que influenciam na nossa formação e na nossa maneira de ser e de agir, enfim, em nossa vida ética.

Podemos ser categóricos em afirmar que na sala de aula, não importa como e onde ela esteja situada, os humanos que ali se encontram estão sendo movimentados por uma gama de situações e circunstâncias muitas vezes desconhecidas e que não temos qualquer poder sobre elas. Simplesmente somos movidos e afetados por estados afetivos, oriundos delas, que repercutem direta e efetivamente em nossas condutas cotidianas, especialmente nas relações que são construídas nesse ambiente.

É bem sintomático nos dias hodiernos notícias e acontecimentos que revelam atitudes bastante violentas das pessoas em sua convivência com os outros. Muitas dessas atitudes se manifestam na escola, constituindo um problema que tem preocupado a todos, inclusive atingindo o processo de ensino e de aprendizagem. Recente pesquisa realizada pelo Sindicato dos Professores do Ensino Oficial do Estado de São Paulo (APEOESP) mostra o aumento nos índices de violência registrados nas escolas estaduais, em 2017, em relação à última pesquisa feita entre 2013/2014. Os dados indicam que $67 \%$ dos pais, $80 \%$ dos estudantes e $85 \%$ dos professores disseram saber de casos de violência em suas escolas estaduais no último ano. Talvez isso explique outras informações obtidas pela pesquisa, ou seja, que $45 \%$ dos pais, $48 \%$ dos estudantes e $37 \%$ dos professores afirmam que não se sentem seguros dentro da escola. Agressão física e verbal, bullying, furto, roubo e discriminação são os tipos de violência mais predominantes sofridos e que são relatados pelos pais, estudantes e professores. Para se ter uma ideia, $44 \%$ dos professores já sofreram algum tipo de agressão verbal (APEOESP, 2017).

Outro levantamento realizado pelo periódico Folha de S. Paulo mostra que a cada dia, em média, quase dois professores são agredidos em seus locais de trabalho. Tendo como fonte os registros policiais realizados no primeiro semestre de 2017, os dados indicam que 178 queixas foram feitas em datas do calendário escolar, ou seja, em dias úteis do período de fevereiro a junho. 
lares. Há educadores atingidos com lixeiras, carteiras escolares, socos, chutes e pontapés. Em ao menos um de cada quatro casos, um aluno foi apontado entre os agressores (FOLHA DE S. PAULO, 2017).

Embora ambas as pesquisas não apontem nessa direção, é possível lançarmos mão de ideias e reflexões produzidas por pensadores como Aristóteles, Freud e Elias para tentarmos, no mínimo, compreender os desafios que são enfrentados e vividos, por exemplo, por professores e alunos em uma sala de aula. Consideramos que esses pensadores trouxeram à ordem do dia ou colocaram em destaque aspectos e dimensões da vida humana que muitas vezes foram desprestigiados ao longo do pensamento filosófico, psicológico e sociológico. Ao não reconhecermos essas dimensões, dificulta-nos olhar o ser humano na sua integralidade e também em sua singularidade, tendo como consequência a impossibilidade de construirmos um ambiente escolar saudável.

Nesse sentido, partimos da ideia de que as paixões, as emoções ou as pulsões pertencem à natureza humana, isto é, para conhecer os homens talvez seja necessário que comecemos a considerar essas dimensões, visto que elas podem indicar o caráter de um indivíduo e de um grupo. Pensamos que foi justamente isso que fizeram os pensadores já referidos. Nesse aspecto, defendemos a ideia de que a melhor maneira de se estabelecer estratégias para influenciar a conduta de uma pessoa está em considerar esse outro lado de sua existência. Isto significa dizer que esses sentimentos habitam e se manifestam nos indivíduos, ou seja, em nós, provocando consequências na nossa vida social que, por sua vez, estimula e motiva as nossas atitudes individuais. Portanto, nada melhor do que articular ou pelo menos expor algumas ideias do campo da filosofia, da psicologia e da sociologia para contribuir nesse processo de compreensão e, quiçá, de enfrentamento dos problemas vividos pelas escolas.

Quando estudamos uma organização social, a tendência predominante é observarmos e diagnosticarmos os costumes, as regras da vida coletiva, como o funcionamento das instituições políticas, religiosas, educacionais, econômicas, enfim, os monumentos que construímos para garantir a existência e a continuidade dos indivíduos e da sociedade. Tudo isso é feito, geralmente, por uma ênfase na dimensão epistemológica, ou seja, quer-se compreender e explicar a realidade por meio de uma representação das coisas e dos acontecimentos em forma de conceitos e teorias. Dito de outro modo, parte-se do pressuposto de que somos seres racionais conscientes, capazes de exercer uma atividade sensível e intelectual dotada do poder de análise e síntese, de representação dos objetos por intermédio de ideias e de avaliação, compreensão e interpretação desses objetos por meio de juízos. Por conseguinte, somos sujeitos do conhecimento que:

\footnotetext{
...se reconhece como diferente dos objetos, cria e/ou descobre significações, institui sentidos, elabora conceitos, ideias, juízos e teorias. Por ser dotado de reflexão, isto é, da capacidade de conhecer-se a si mesmo no ato do conhecimento, o sujeito é um saber de si e um saber sobre o mundo, manifestando-se como sujeito percebedor, imaginante, memorioso, falante e pensante (CHAUÍ, 2003, p. 130).
} 
Portanto, retomar sentimentos como as paixões, as emoções e as pulsões, tratadas neste texto como próximas ou pertencentes à mesma dimensão humana, reveste-se de uma significância fundamental para lançar luz sobre os problemas e os dramas enfrentados e vividos no ambiente escolar, como já vimos.

Em um primeiro momento, esses sentimentos podem parecer elementos estranhos a um estudo sociológico, restritos que estavam ao domínio filosófico, tendo em vista que Aristóteles e Platão foram os primeiros pensadores que abordam e descrevem o papel das paixões na constituição humana, inclusive considerando-as empecilhos para a obtenção do conhecimento verdadeiro, especialmente na filosofia platônica, que "primeiro colocou em um mesmo plano paixões e doenças, inaugurando uma longa tradição interpretativa desse fenômeno" (LACERDA, 2013, p. 15); ou restritos ao domínio psicológico-psicanalítico moderno, que tem em Freud um dos seus maiores expoentes, pois ele tenta explicar os seus mecanismos de funcionamento e os seus efeitos na conduta humana. Ainda no campo da filosofia, outros pensadores também trataram o tema das paixões, como: Cícero, Bergson, Descartes, Rousseau, Hobbes, Spinoza, Kant, Hume, Montaigne, Maquiavel e Voltaire (KORICHI, 2000).

Por sua vez, se partirmos das teorias sociológicas clássicas, como a de Marx, Weber e Durkheim, a abordagem da temática não é feita de forma direta e explícita, o que exige um esforço de organização do que foi apresentado de maneira esparsa. Como ilustração, podemos tomar a análise que Marx faz do dinheiro, considerando como um mediador por excelência das relações sociais, determinando, assim, o estabelecimento dos vínculos afetivos e passionais entre as pessoas. Para ele, o mundo dos afetos teria perdido seu valor incomensurável que talvez pudesse propiciar sentimentos elevados para nivelar a inefabilidade do amor ao plano material das determinações pecuniárias, como uma relação comercial. Ao contrário, os caracteres éticos da pessoa são transformados imediatamente graças ao poder financeiro, que corrige, modifica, aprimora, potencializa e diviniza todas as coisas. Para Marx:

\footnotetext{
...o que é para mim pelo dinheiro, o que eu posso pagar, isto é, o que o dinheiro pode comprar, isto sou eu, o possuidor do próprio dinheiro. Tão grande quanto a força do dinheiro é a minha força. As qualidades do dinheiro são minhas — de seu possuidor - qualidades e forças essenciais. O que eu sou e consigo não é determinado de modo algum, portanto, pela minha individualidade (MARX, 2004, p. 159).
}

Como consequência, a finalidade central do capitalismo afetivo seria garantir o prazer pessoal, sem levar em conta a natureza da relação e sua qualidade singular potencialmente transformadora da própria vida humana. Ou seja, a presença do outro - uma relação de alteridade - é um mero acréscimo gratificante que se inscreve em uma economia sexual puramente narcísica. Viveríamos em um mundo "sem vínculos" e de relacionamentos "sem compromisso".

Max Weber, por sua vez, quando expõe de modo ideal-típico as quatro determinantes principais da atividade social, distingue e define aquilo a que chama um determinismo 
afetivo das condutas sociais, onde as paixões, as emoções e os sentimentos desempenham um papel fundamental (AMÂNDIO, 2004, p. 369). Para ele, a ação social pode ser determinada de: 1) modo racional referente a fins; 2) modo racional relativo a valores 3 ) modo tradicional e

4) modo afetivo, especialmente emocional: por afetos ou estados emocionais atuais (...) Age de maneira afetiva quem satisfaz sua necessidade atual de vingança, de gozo, de entrega, de felicidade contemplativa ou de descarga de afetos (seja de maneira bruta ou sublimada)" (WEBER, 1998, p. 15. Grifos do autor).

Grosso modo, da obra desses pensadores e de outros, como Simmel, Elias, a Escola de Frankfurt, Foucault, Bourdieu e Habermas, ao quererem construir representações globais da realidade e tomar consciência da condição humana submetida a mudanças sem fim e em ruptura com a estabilidade da tradição, penso que é possível extrair indícios significativos de que esses sentimentos têm aí a sua presença garantida: seja na vida pessoal desses cientistas, seja mesmo no terreno de onde retiraram o material para as suas reflexões, isto é, o mundo social e as suas relações.

Os grandes teóricos e filósofos da vida política, de Platão e Marx, estavam atentos a esta dimensão afetiva da história e à necessidade de buscar meios de analisá-la. Montesquieu, por exemplo, formulava a hipótese de que para cada sistema político corresponde uma paixão política dominante, participando na manutenção e na regulação do sistema: a virtude, a honra, o temor. Alexis de Tocqueville, comparando as sociedades europeias com a vida social americana, notava a importância do que ela chamava de "as paixões gerais e dominantes" de uma sociedade. Mas é, talvez, na obra de Marx, contrariamente à vulgata economista do marxismo, que vemos bastante sublinhado a importância das diversas dimensões da afetividade política (ANSART, 1983, p. 12).

Para o objetivo deste texto, vamos trabalhar com os três autores já citados, isto é, Aristóteles, Freud e Elias, com a finalidade de trazer para o debate esses estados afetivos como importante recurso para se compreender determinada formação social e a conduta individual de cada um de nós e pensá-los como uma experiência a ser considerada no processo de formação, constituição e ação humana, especialmente dentro de uma sala de aula.

Inicialmente, trataremos das ideias de Aristóteles, que considera as paixões um elemento fundamental da natureza humana, sobretudo na e para a constituição do sujeito ético e moral. Em seguida, trazemos a contribuição de Freud, que as toma como uma força submersa na constituição do homem e que indica que não somos senhores em nossa própria casa, contradizendo o fato de pretendermos ser o senhor do nosso próprio destino por meio de um $e u$, isto é, de uma consciência que tudo faz, que tudo escolhe, que tudo pensa. Por fim, exploraremos as reflexões de Norbert Elias, que em alguns de seus textos considera que o controle das emoções está associado ao processo civilizatório, explicando que esse controle não é um ato ou uma ação individual, mas resultado da movimentação da própria 
sociedade em seus aspectos políticos (Estado), cultural (Educação) e econômicos (tributação/imposto e o poder monetário).

Com este texto, pretendemos indicar que a filosofia, a psicologia e a sociologia podem dialogar e contribuir na compreensão e enfrentamento dos acontecimentos que nos atingem nos dias atuais. Abordando essa questão, Fréderic Lordon (2015), em seu livro A sociedade do afetos: por um estruturalismo das paixões, considera que alguma coisa está acontecendo com as "Humanidades", ou seja, que acontecimentos significativos, deslocamentos de fronteiras e novos recortes estão unindo campos que antes seguiam separados.

Para ser mais preciso, se era outrora espaço de escaramuças recorrentes, o fato novo consiste em aproximações atuais que vêm se esboçando. (...) Sem dúvida, o movimento é, por ora, minoritário, mas essas hibridações, que teriam há pouco passado por transgressões incongruentes, aparecem mais e mais como uma forma evidente do trabalho intelectual, se se trata de pensar o homem e a sociedade (LORDON, 2015, p. 25-26).

E no caso dos desafios e dramas presentes no campo educacional, e aqui estamos nos referindo à violência nas e/ou a partir das escolas, nos parece que a aliança dessas três áreas do saber, tomando o tema das paixões ou das pulsões ou das emoções, pode oferecer algumas respostas ou encaminhamentos de saídas.

\title{
As paixões em Aristóteles e a fOrmaÇão étiCa
}

Na filosofia moral aristotélica, as páthe (emoções, paixões) são estados afetivos fundamentais na constituição das ações humanas. ${ }^{2}$ Elas indicam o caráter contingente da nossa própria existência. Se quisermos bem agir eticamente, é necessário que levemos em consideração a presença das paixões.

\begin{abstract}
A paixão é um acidente ou um predicado que tem a peculiaridade de ser sempre contingente. Em primeiro lugar, porque, como diz a própria definição de contingência, depende do encontro fortuito ou casual de nosso corpo com os objetos de prazer e dor; em segundo, porque, dependendo do estado de nosso corpo e de nossa alma, um mesmo objeto tanto pode causar prazer como dor (...) A presença da paixão como um elemento essencial da ação moral faz com que a tarefa da ética seja educar nosso desejo para que não se torne vício e colabore com a ação feita por meio da virtude. Em outras palavras, Aristóteles não expulsa a afetividade, mas busca os meios pelos quais o desejo passional se torne desejo virtuoso (CHAUÍ, 2011, p. 444).
\end{abstract}

2 Embora o tema apareça na Ética a Nicômaco, é na Retórica que Aristóteles “analisa mais detidamente as emoções humanas, escrevendo por assim dizer o primeiro tratado de um gênero que terá particular acolhida na reflexão filosófica até a modernidade, o tratado das paixões" (ZINGANO, 2008, p. 121). 
A partir dessa compreensão, observamos uma diferença essencial com o pensamento platônico, pois este atribui à razão o poder apodítico para controlar, dominar e governar os desejos. Nesse sentido, Platão procura formular uma ideia universal do Bem como uma entidade inteligível separada do sensível, isto é, "a Forma universal da Bondade, como se o Bem fosse o mesmo para todos os seres e como se pudesse ser alcançado apenas pela via teorética" (CHAUÍ, 2011, p. 442).

Na perspectiva aristotélica, as ações humanas em direção à felicidade, como fim da ética, não são como as operações naturais, que seguem um curso imutável, necessário e válido para todos em todo tempo e lugar. Ao contrário, elas são apenas possíveis, isto é, uma busca resultado de um processo deliberativo e de uma escolha voluntária, que traz efeitos muito variáveis e múltiplos. Disso decorre que a ética é uma ciência prática ou ciência da práxis humana, ou seja, um saber que tem por objeto a ação e, portanto, ela pertence ao campo da ciência política. Como ciência, a política tem por objeto a felicidade humana e se divide em ética - que se preocupa com a felicidade individual do homem na pólis - e na política propriamente dita - que se preocupa com a felicidade coletiva da pólis. Com a sua Política, Aristóteles pretende justamente investigar as formas de governo e as instituições capazes de garantir uma vida feliz ao cidadão, na pólis. Por isso mesmo, a política situa-se no campo das ciências práticas, ou seja, aquelas ciências que buscam o conhecimento como meio para ação.

No entanto, cabe observar que para Aristóteles a ciência tem os seus limites. E isso serve também para a política e, por extensão, para a ética. Para ele, na ciência política as ações belas e justas sobre as quais ela se debruça admitem grande variedade e flutuações de opiniões, de forma que se pode considerá-las como existindo por convenção, e não por natureza. O mesmo vale para os bens que buscamos no campo ético, pois neles não há uma precisão, uma exatidão nas ações que me levaria a resultados plenamente satisfatórios e previamente determinados.

No capítulo 3 do livro 1 da Ética a Nicômaco, Aristóteles parece querer fazer algumas observações que indicam o espírito que o assunto deve ser investigado, estipulando certa metodologia. Assim, o máximo a que podemos chegar é a aproximações e linhas gerais e não a conclusões precisas, pois o assunto é delicado e deve ser estudado a partir de probabilidades. A natureza da ciência política estaria assentada em afirmações impossíveis de serem demonstradas rigorosamente. É pressuposto ou exigência de quem investiga essa área do conhecimento, isto é, as ações humanas, que seja dotado de experiência sobre os fatos da vida, pois:

...o homem instruído a respeito de um assunto é um bom juiz em relação ao mesmo, e o homem que recebeu uma instrução global é um bom juiz em geral. Consequentemente, um homem ainda jovem não é a pessoa própria para ouvir aulas de ciência política, pois ele é inexperiente quanto aos fatos da vida e as discussões referentes à ciência política partem destes fatos e giram em torno deles (ARISTÓTELES, 1987, p. 10). 
Nessa perspectiva, ele faz um alerta: deixar-se ser levado ou restringir-se apenas às emoções, como muitas vezes deseja quem está na plena juventude, não é proveitoso, visto que "quem deseja e age segundo a razão o conhecimento de tais assuntos é altamente útil" (ARISTÓTELES, 1987, p. 10). Portanto, a quem pretende estudar os assuntos dessa ciência é sugerido que se conduza tomando em consideração essas premissas, ou seja, de que nela não há provas e demonstrações, como na matemática, bem como, devemos levar em conta que nem a razão pode tudo e nem que devemos ignorar a nossa constituição passional.

No que diz respeito às paixões, o pensamento aristotélico, todavia, não as considera como algo revestido de um caráter terrível, mas, sim, como respostas afetivas normais que damos nas circunstâncias que nos chegam. Fenômenos puramente humanos, as paixões nos dão a possibilidade de nos governarmos. "O virtuoso, [ao invés de refrear as paixões], age corretamente, mas em harmonia com suas paixões, porque ele as dominou de uma vez por todas. Não só aprendeu a agir de modo conveniente, mas a sentir o páthos adequado" (LEBRUN, 1987, p. 20).

O páthos, como característica e lugar do humano, exprimiria, assim, a contingência, a alternativa e a multiplicidade. Nesse aspecto, a importância das paixões na constituição da vida ética se sobressai. Ao contrário de uma tradição que as considerava como obstáculo e impedimento à ação, Aristóteles as toma como oportunidade e expressão não só do humano, mas da liberdade humana em direção à virtude. As paixões nos dão as condições de nos atualizarmos, realizando a nossa finalidade essencial - a busca do Bem -, diferente de uma planta que já tem o seu fim prescrito.

\footnotetext{
A atualização faz parte da própria natureza do sujeito, enquanto o páthos tem o sentido provisório de levar o homem a tomar conhecimento dessa substância (...) O páthos é, em suma, o momento contingente e problemático que busca reencontrar a natureza das coisas, sua finalidade própria, determinada pela essência. Preserva a identidade do sujeito graças à diferença daquilo que não é ele, mas que, mesmo assim é (MEYER, 2000, p. XXXIII-XXXIV).
}

Na concepção de vida ética aristotélica, as paixões são elementos essenciais para a edificação do sujeito virtuoso, cabendo a nós, homens, nos responsabilizarmos pela educação dessas tendências que estão implantadas em nossa natureza, isto é, somos responsáveis pelo mau uso que delas podemos fazer. Essa educação, porém, não é uma simples repressão dos desejos insaciáveis e que quer se alimentar de tudo, mas deve considerar o páthos como algo em consonância com o lógos, em que o papel deste consiste exatamente em escolher os fins e proporcionar-se os meios. A virtude é o resultado do exercício da razão no homem.

Devemos aprender a viver em conformidade com o lógos, mas sem esquecer que as paixões continuam sendo a matéria de nossa conduta - e que só a propósito de seres passionais se pode falar em conduta razoável. Paixão e razão são inseparáveis, assim como a matéria é inseparável da obra e o mármore da estátua (LEBRUN, 1987, p. 22). 
As paixões representam, assim, o outro que há em nós ou, se preferir, o outro lado da mesma moeda, e que sem ele perderíamos algo de nós mesmos. Considerá-las apenas como algo irracional, que deve ser eliminado e extirpado, reduzindo-se ao caráter apodítico do lógos, é extrair a nossa própria humanidade.

\begin{abstract}
A paixão é a alternativa, sede da ordem daquilo do que é primeiro para nós, dissociada essa ordem do que é em si e irredutível a este. Ela é, por isso mesmo, o lugar do Outro, da possibilidade diferente do que somos afinal; o individual [contingente] por oposição ao universal [necessário] indiferenciado. A paixão é, portanto, relação com o outro e representação interiorizada da diferença entre nós e esse outro. A paixão é a própria alteridade, a alternativa que não se fará passar por tal, a relação humana que põe em dificuldade o homem e, eventualmente, o oporá a si mesmo. Compreende-se, nessas condições, que a paixão remete às soluções opostas, aos conflitos, à diferença entre os homens. A oponibilidade que une e desune os homens e precisamente o passional, a contingência que os libera ao mesmo tempo que pode entregá-los ao que destrói e ao que os subjuga (MEYER, 2000, p. XXXV).
\end{abstract}

Dessa maneira, uma vida ética que pressupõe a existência das paixões precisa aprender a considerar o prazer e o sofrimento, aquilo que é flutuante e que muitas vezes nos desestabiliza e que nem sempre temos controle. Como estado da alma, as paixões são ou provocam confusões, mas que, se bem educadas, podem ser contrariadas, invertidas e como representação do Outro, nos colocar no exercício pleno de uma liberdade responsável. Visto que não é possível viver sem elas, como querem algumas concepções éticas, o que nos compete é trabalharmos para conviver e nos governar com ou a partir delas.

No caso específico da violência que ocorre na sociedade e, principalmente nas escolas, a tarefa de cada um de nós é reconhecer que somos dotados de paixões e que todo comportamento do indivíduo tem suas raízes nelas. Se ignorarmos a sua existência e buscarmos extirpá-las a qualquer custo, o resultado é certa deficiência no processo de formação do nosso caráter. Quando uma pessoa age de forma violenta, isso demonstra a sua incapacidade de dominar e controlar as suas paixões. Portanto, nesse caso, é razoável encontrar meios para dosá-las e educá-las e que toda energia de que as paixões são portadoras sejam utilizadas de maneira adequada e na medida certa, de acordo com os movimentos que as circunstâncias nos apresentam.

A educação é mais do que a simples repressão dos desejos. Ela deve levar os "homens bem nascidos" a dominar suas paixões, isto é, a torná-los aptos a utilizá-las adequadamente. No homem bem-educado, o páthos não é uma força que colocará permanentemente obstáculos à alma razoável: ele está a serviço do logos e em consonância com ele. A boa educação faz de mim um ser tão perfeitamente "condicionado" que as paixões estão permanentemente à minha disposição (LEBRUN, 1987, p. 21. Grifos do autor). 
Em uma sala de aula, quando um aluno agride um colega ou um professor, a atitude mais apropriada é procurar compreender quais as suas causas passionais e, conhecendo-as, construir mecanismos que possam favorecer o bom uso desses sentimentos. Se ele não sabe se conduzir sozinho cumpre à escola realizar esse papel. Não é suficiente estabelecer um conjunto de regras previamente e pedir que as pessoas as cumpram imediatamente. É necessário também levar em conta que somos possuidores de sentimentos como a cólera, o ódio, a alegria, a tristeza, o medo etc., e que eles estão na origem de nossas ações cotidianas. Aliás, isso não poderia jamais nos surpreender se considerássemos que somos seres além de pensantes, somos seres passionais, ou seja, lógos e páthos nos constituem e nos movimentam, inclusive para agirmos violentamente.

Tal como Freud, que veremos a seguir, é fundamental deixar claro que não é razoável estabelecer uma hierarquia ou um maniqueísmo entre as diversas faculdades do psiquismo e da natureza humana, mas sim uma tentativa de que aspectos conscientes e inconscientes (razão e paixão, por exemplo) sejam ambos levados em consideração quando nos dedicamos a compreender e refletir acerca das realizações humanas no decorrer da vida e ao longo dos tempos.

\title{
As pulsões em Freud e o homem CiVilizado
}

Freud foi um dos pensadores que também se dedicaram a descrever e tentar compreender as forças psíquicas e somáticas que estão na constituição do homem, dando o nome de pulsões (Trieb), ${ }^{3}$ com o objetivo de compreender e desenvolver a noção de inconsciente. Conforme destaca Lacerda (2013, p. 48):

\begin{abstract}
....a história filosófica das paixões recebeu grande influência, na passagem do século XIX ao século XX, da teoria psicanalítica (...) As pulsões de vida e de morte da teoria freudiana, designadas pelos nomes gregos Eros e Thanatos (extraídos da mitologia grega), poderiam ser vistas como equivalentes psicanalíticos das paixões ou pelo menos de duas paixões básicas, o amor e o ódio, com toda a ambivalência que essas paixões podem carregar, já que um mesmo objeto é amado e odiado (o mesmo objeto que satisfaz também traz frustrações).
\end{abstract}

\footnotetext{
“Uma tradução aceitável para a palavra 'Trieb', em português, inclusive no uso que Freud faz dela, seria 'impulso' (...) A correspondência semântica entre 'Trieb' e 'impulso' é bastante grande, e 'impulso' parece servir para todas as acepções de 'Trieb' que analisamos. Tem, entretanto, a desvantagem de não ter necessariamente uma conotação relacionada à ideia freudiana de uma fonte somática. Além disso, sobretudo na forma adjetiva 'impulsivo', tem a conotação de algo irrefletido e que leva a uma reação imediata, o que não se aplica a todos os derivados da pulsão, especialmente aos que correspondem a um processo de sublimação. Assim, parece ser mais conveniente o emprego do neologismo "pulsão", já consagrado em psicanálise, que tem a vantagem de poder se revestir melhor das conotações específicas do termo freudiano. Esta tradução, certamente, também deve ser preferida a 'instinto'." O termo "pulsão" foi adotado, em português, a partir do francês, no qual "pulsion" era um arcaísmo, que foi revivido pela psicanálise. Este termo substituiu quase completamente a palavra "instinct", usada nas traduções francesas mais antigas. Em inglês, "drive" foi proposto como a tradução mais próxima de "Trieb", derivando inclusive da mesma raiz etimológica. No entanto, a tradução mais frequente, em inglês, é ainda "instinct" (GOMES, 2001, p. 251).
} 
A psicanálise considera a ideia de que não somos senhores em nossa própria casa, contradizendo o fato dos homens pretenderem ser o senhor do seu próprio destino por meio de um eu, de uma consciência ou de uma racionalidade unívoca, instrumental e ordenadora. Segundo ele, o inconsciente é essa força obscura que arranca e impede o homem de coincidir consigo mesmo, enquanto os filósofos da consciência, embora tenham reconhecido essas forças, que aqui chamarei de pulsões, para usar a terminologia freudiana, não duvidavam de que seríamos capazes de controlá-las e extirpá-las ou, no mínimo, reprimi-las por meio da razão.

Porém, o melhor, segundo Freud, é reconhecer e tentar compreender que o nosso psiquismo, e que estende à nossa existência, é movido pelo trânsito de duas pulsões (categoria de energia que impele corpo e mente ao movimento) contraditórias e complementares. Se, por um lado, temos a pulsão de vida (Eros), que conduz o organismo ao movimento e à construção de relações que visam uma melhora da qualidade de vida e leva o sujeito a conviver de maneira mais harmoniosa com a natureza que o cerca e com sua subjetividade, por outro lado, - e de forma simultânea - nos deparamos com a pulsão de morte (Thanatos), cuja energia impele o organismo à desintegração e à eliminação de qualquer tipo de tensão que não o conduza ao chamado grau zero de excitação, ou seja, ao repouso absoluto e à ausência de necessidades de qualquer espécie (OLIVEIRA, 2016, p. 33).

Se Freud, por seu lado, reconhecia certa racionalidade dessas duas forças que agem em nós sem que estejamos conscientes, muitos filósofos sustentaram que as paixões pertencem ao campo da irracionalidade. De Platão a Kant, as paixões foram denunciadas com fervor como sendo más em si, viciosas e irracionais. Se quisermos viver bem, viver a vida de seres racionais, devemos nos desembaraçar delas. Em outras palavras, eliminá-las ou reprimi-las seria o melhor caminho e não satisfazê-las, embora isso possa produzir certo mal-estar, conforme diagnostica o próprio Freud em seu texto O mal-estar na civilização (1997).

Nessa obra, Freud aponta que, embora os seres humanos queiram alcançar a felicidade e mantê-la permanentemente, ou seja, realizar suas pulsões de vida, o máximo que atingem é uma felicidade ou prazer momentâneo. O caráter efêmero do prazer impede o alcance e a sustentação do estado desejado. Estaríamos, segundo ele, constantemente experimentando situações de frustração. Ou seja, nem sempre temos o domínio do que vai acontecer conosco e vivemos, ou pelo menos deveríamos escolher, uma forma de vida em que houvesse um equilíbrio entre essas duas instâncias. É isso que exige a civilização.

O grande passo civilizatório deve ser ainda o de substituir o poder e a liberdade de cada indivíduo pelos da comunidade, o que não pode ser feito sem a imposição de restrições das possibilidades de satisfação até então desconhecidas pelos indivíduos que, doravante, passam a contribuir, não sem antes se sentirem contrariados, para a construção social (BOCCA \& CAROPRESO, 2011, p. 13).

É nesse sentido que Freud desenvolve um arcabouço teórico que lhe direciona a questionamentos acerca do espaço e da influência da razão em nossas vidas e nos desdobramentos de nossas ações no cotidiano. Pautado em métodos científicos - ainda hoje 
questionados, mas não refutados - Freud procura demonstrar que a consciência humana e a razão/racionalidade constituem a parte mais fraca e diminuta de nossa vida psíquica. Dessa forma, sustenta que a existência de aspectos pulsionais, inconscientes e primitivos no psiquismo humano, são responsáveis por uma série de ações e posturas corporificadas nas relações humanas. Afirma em sua obra:

\begin{abstract}
A Psicanálise propõe mostrar que o Eu não somente não é senhor na sua própria casa, mas também está reduzido a contentar-se com informações raras e fragmentadas daquilo que se passa fora da consciência, no restante da vida psíquica (...). A psicanálise se recusa a considerar a consciência como constituindo a essência da vida psíquica, mas nela vê apenas uma qualidade desta, podendo coexistir com outras qualidades e até mesmo faltar (FREUD, 1996, p. 47).
\end{abstract}

Com isso, Freud de maneira alguma desconsidera a existência e a importância da razão, mas acaba por relativizar sua predominância e supremacia nas escolhas realizadas pelas pessoas. Estamos, portanto, às voltas com aspectos pouco considerados nas relações humanas, na medida em que as lacunas deixadas pelos limites da racionalidade acabam por serem preenchidas por elementos de ordem inconsciente e pulsionais. Esse aspecto inconsciente de nossa vida psíquica conduz a uma série de situações nas quais a racionalidade pouco pode fazer para evitar a expressão de conteúdos inconscientes e os afetos - igualmente inconscientes - deles advindos.

Assim, podemos conjecturar que atitudes de violência são passíveis de serem compreendidas a partir dessa perspectiva. As pulsões, do ponto de vista da teoria psicanalítica freudiana, abrangem toda a vida de uma pessoa, desde a atitude de uma criança em relação aos seus pais amados até as relações amorosas, em que a entrega de si é total, relembrando a relação do hipnotizado com o hipnotizador. Como realização das pulsões sexuais, elas manifestariam o lado compulsivo do amor, na medida em que um indivíduo mostra a sua atração anormal por outro, muitas vezes, inclusive, de maneira violenta. Semelhante a um delírio, a experiência da paixão pode indicar um estado prototípico de uma psicose: a perturbação é plena. As proezas psíquicas levam o sujeito a uma estupenda dedicação ao objeto, fazendo que a mobilização da libido atinja um grau tão elevado, que ocorre uma espécie de abandono da sua própria personalidade.

Na paixão, a fascinação faz que o objeto amado goze de certa liberdade ao olhar crítico, em que a idealização é tamanha que mais parece ampliar a distância entre o objeto e o sujeito do desejo. Não há sublimação, ou seja, a ultrapassagem desses sentimentos em direção às dimensões artísticas, religiosas e científicas. Marcada pela mobilidade, ela inquieta, exigindo a descoberta contínua de novos aspectos próprios ao seu objeto; o apaixonado constrói uma crença indefectível em um modelo que não pode ser demonstrado.

De toda forma, e ainda permanecendo com Freud, a noção de inconsciente indica os limites do poder soberano da razão e da consciência, o que exige uma reconfiguração de nossa crença e postura de que a nossa existência, os nossos pensamentos e as nossas condutas são orientados por esses poderes. Desse ponto de vista, temos que lidar agora com 
a ideia de que a consciência não pode tudo. Além de racionais, temos que considerar que somos também resultados de impulsos e de desejos inconscientes.

Em uma perspectiva ética, as conclusões psicanalíticas freudianas nos mostram que:

\begin{abstract}
...somos resultados e expressão de nossa história de vida, marcada pela sexualidade insatisfeita, que busca satisfações imaginárias sem jamais poder satisfazer-se plenamente. Não somos autores nem senhores de nossa história, mas efeito dela. [Mostram-nos] também que nossos atos são realizações inconscientes de motivações sexuais que desconhecemos e que repetimos vida afora (CHAUİ, 2003, p. 329).
\end{abstract}

Visto que já não mandamos mais em nós e que as nossas vontades não estão sob o nosso domínio e, assim, qualquer ação por dever não seria possível, rapidamente podemos concluir que desse processo fica bastante difícil conceber uma proposta ética. Dito de outra maneira, como a consciência poderia responsabilizar-se pelo que desconhece e que jamais se torna consciente? Como preservar e garantir os valores morais nessa situação? Não há como preservar e como garanti-los, embora a tradição racional sempre tenha considerado os desejos e os impulsos inconscientes como passíveis de serem controlados, impondo deveres, valores e fins éticos que se portariam como regras e normas repressivas, anulando, quase por completo, a nossa autonomia e o nosso ser real. Ou seja, o inconsciente desconhece valores morais e muitas de nossos comportamentos que a moralidade racional toma como imorais "são realizados como autodefesa do sujeito, que os emprega para defender sua integridade psíquica ameaçada. Se são atos moralmente condenáveis, podem, porém, ser psicologicamente necessários" (CHAUÍ, 2003, p. 329).

Entre todos os significados possíveis dos conceitos de paixão, pulsão ou emoção, chama a atenção o fato de que em ambos carregam em si semelhanças importantes. Vinculam-se a eles elementos que se encontram fora do controle racional e, ainda, cuja intensidade ultrapassa o limite do tolerável e, talvez, até do saudável. Vida e morte, construção e destruição, movimento e repouso, são forças que agem nos sujeitos de dentro para fora sem que se possa fazer muita coisa para impedir suas expressões. Para a Psicanálise, nos tornamos menos impotentes frente a esses aspectos quando passamos a prestar mais atenção a eles e a considerar suas influências em nossas ações cotidianas. Longe de controlá-los, a proposta de levá-los em consideração pode auxiliar na coerente avaliação e distribuição das responsabilidades e limitações de cada um nos fatos e experiências das quais faz parte.

A Psicanálise, bem como os estudos mais recentes sobre Educação que interrogam as novas formas de subjetividade, os modos contemporâneos de sintoma e de entendimento das incertezas, atos e éticas do gênero humano, vêm apostando numa fértil conexão entre esses dois campos de conhecimento e saber (PEREIRA; SANTIAGO; LOPES, 2009, p. 142).

E não poderia ser diferente, visto que o tempo vem consagrando a Psicanálise como uma importante ferramenta de leitura de mundo, possibilitando uma compreensão mais 
ampla dos fenômenos humanos e permitindo intervenções diferenciadas. Havendo nos processos educativos uma rica variedade de humanidade, a utilização da Psicanálise para tentar compreender e intervir nos ambientes educacionais e em seus desdobramentos parece algo, até certo ponto, natural (FREUD, 1996).

Tanto no âmbito filosófico, sociológico como psicanalítico, com os termos paixão, emoção e pulsão, podemos depurar um elemento comum, ou seja, uma força que impele o sujeito ao movimento. $\mathrm{O}$ fato de impelir ao movimento denota a existência de uma espécie de energia que se destina a determinado fim. A respeito da existência dessa energia, temos a possibilidade de interpretá-la como sendo manifestações das pulsões psicanalíticas, das paixões filosóficas e das emoções, como analisada por Norbert Elias.

O que quisemos mostrar com essas ideias freudianas foi que a ação humana não depende totalmente do controle racional e das deliberações conscientes do ser humano, mas, sim, são determinadas por elementos inconscientes e por pulsões, paixões, emoções, desejos, dos quais não temos poder e domínio, mas que nos constituem e nos movimentam somática e psiquicamente. Ou melhor, que a nossa subjetividade não é apenas pensante, consciente e racional. Portanto, ao invés de excluir essas forças, deveríamos levá-las em conta para termos uma noção mais completa dos humanos e, assim, quem sabe, compreendermos as condutas de professores e alunos em uma sala de aula, inovando as atitudes e as práticas pedagógicas, e até enfrentando e compreendendo melhor os casos e atos de violência que se manifestam na e a partir da escola. Mesmo porque as dimensões passionais, pulsionais e emocionais, que nos constituem e que nos caracterizam, não mobilizam apenas os indivíduos, mas são capazes de construir e revelar toda uma civilização, isto é, fazer parte do próprio processo civilizatório, como nos ensina Norbert Elias e que veremos a seguir.

\section{As emoções em Norbert Elias e o Processo CiVILIZATório}

Antes de tudo, para se entender a questão das emoções em Norbert Elias é preciso ter claro alguns aspectos. Primeiro, que Elias não trabalha com um conceito "puro" de emoções e, sim, com a ideia de controle das emoções e, em segundo lugar, que o conceito de controle das emoções só adquire seu pleno significado se compreendido no contexto da teoria dos processos de civilização, desenvolvida por ele no início do século $\mathrm{XX}$ e, por último, entender que os fundamentos da ideia de controle das emoções, da forma como é explicitada por Elias, tem como principal referencial teórico exatamente Freud, cuja ideia de emoções ou de pulsões foi abordada no tópico anterior (COSTA; ENDO, 2014).

Assim, a escolha da teoria dos processos de civilização como principal referencial para falar das emoções em Elias deu-se por dois motivos. Primeiro, por essa teoria ter sido considerada pelo próprio Elias como "o eixo em torno do qual gira toda a sua contribuição sociológica", contendo, também, o desenvolvimento da ideia do controle das emoções (ELIAS, 1997, p. 7). O segundo diz respeito a uma característica ímpar presente nos trabalhos de Elias, que é a de conseguir entrelaçar os níveis micro e macro de análise social, explicitado, com maior ênfase, no livro $O$ processo civilizador. 
$\mathrm{Na}$ teoria dos processos de civilização proposta por Elias, constitui um erro querer separar as transformações gerais sofridas pelas sociedades e as alterações ocorridas nas estruturas de personalidade dos indivíduos que a formam, visto que a relação entre esses dois tipos de alterações é uma relação de correspondência mútua. Um dos pontos essenciais da teoria de Elias é mostrar a impossibilidade de pensarmos os conceitos de indivíduo e de sociedade como duas categorias separadas e/ou antagônicas. Para Elias, as "estruturas de personalidade e da sociedade evoluem em uma inter-relação indissolúvel", sendo que a mudança "nas estruturas de personalidade é um aspecto específico do desenvolvimento de estruturas sociais" (ELIAS, 1994, p. 221).

Sem jamais pensar os conceitos de indivíduo e sociedade como duas instâncias separadas e/ou antagônicas, visto não existirem sociedades sem indivíduos, nem indivíduos que não formem sociedades, a teoria dos processos de civilização proposta por Elias baseia-se na defesa de que toda e qualquer transformação ocorrida na estrutura da personalidade do ser individual (psicogênese), produz uma série de transformações na estrutura social em que o indivíduo está inserido.

Da mesma maneira, as diversas transformações que ocorrem constantemente nas estruturas das sociedades (sociogênese), especialmente nas relações sociais, produzem alterações nas estruturas de personalidades dos seres individuais que a compõem. Para Elias, de modo algum os processos de civilização são compostos por uma série de relações causais, muito ao contrário, o que Elias afirma, permanentemente, é que os processos de civilização da sociedade ocidental emergem da constante correspondência entre as modificações das estruturas de personalidade e as alterações das estruturas sociais, sem que seja possível identificar um ponto inicial para esse processo.

Como processo de desenvolvimento do indivíduo, Elias entende que o processo de civilização "constitui uma mudança na conduta e sentimentos humanos rumo a uma direção muito específica". Tais mudanças, apesar de não terem sido intencionais ou planejadas, não implicam uma "mera sequência de mudanças caóticas". O que Elias quer dizer é que quando analisamos o conjunto histórico, não podemos dizer que as mudanças ocorridas, seja no âmbito individual ou social, em direção a uma nova figuração, foram racionalmente planejadas, mas também não podemos reduzir essas mudanças "ao aparecimento e desaparecimento aleatórios de modelos desordenados" (ELIAS, 1993, p. 193-194).

Partindo da ideia de que a estrutura do comportamento humano, que chamamos de civilizado, está intrinsecamente relacionada com a estrutura das sociedades ocidentais modernas, que chamamos de Estados nacionais, Elias entende que a civilização resulta, também, de um processo de mudanças no nível de controle das emoções, nível esse que também está intrinsecamente relacionado com o crescente grau de entrelaçamento e interdependência entre as pessoas que compõem a sociedade. Para Elias, o nível de controle das emoções de qualquer sociedade é diretamente proporcional ao grau de "civilidade" dessa sociedade, ou seja, quanto mais elevado for esse patamar, tanto mais distante essa sociedade estará da barbárie.

Por sua vez, Elias é taxativo ao constatar a impossibilidade da existência de qualquer sociedade que consiga sobreviver sem a existência de dois tipos de controle das emoções, o 
individual, na forma de autocontrole, ${ }^{4}$ e o controle social das emoções, na forma de um código de conduta e de um padrão de comportamento. O primeiro tipo ajuda a mostrar ao indivíduo qual o padrão de comportamento mais adequado para a sua vida social, já o segundo tipo mostra à sociedade, formada por seres humanos detentores, individualmente, de um mesmo nível de controle das emoções, que aquele indivíduo pode viver, e conviver, em sociedade.

Elias analisa, com base em interessante material empírico, as mudanças de comportamento ocorridas entre os séculos XIII e XVI. Nesse intervalo de tempo, temos uma sensível mudança de atitude em relação a uma série de necessidades naturais dos indivíduos. $\mathrm{O}$ comportamento à mesa, o costume de cuspir e assoar o nariz, o sono, a vida sexual, a agressividade, etc. passaram a ser regulados de forma a servir de sinal de refinamento e civilidade. Uma outra etapa do processo civilizatório se apresenta quando, por força da crescente divisão do trabalho e acirramento da competição social, o controle externo é substituído pelo controle interno. Apenas com este último desenvolvimento a regulação da vida pulsional atinge o caráter evidente que percebemos hoje. Só então o controle do comportamento individual atinge o nível da sociedade democrática e industrial moderna. Agora, autocontrole transforma-se em princípio da saúde mental e física e é internalizado por cada um dos indivíduos (SOUZA, 1999, p. 67).

No âmbito da teoria dos processos de civilização de Elias, dois conceitos não podem ser esquecidos, e que são os conceitos de figuração e de interdependência. O conceito de $f$ guração deve ser entendido como o resultado "do entrelaçamento de incontáveis interesses e intenções individuais", possuam eles direções convergentes ou divergentes, cujo resultado é "algo que não foi planejado nem foi intenção de qualquer um desses indivíduos, mas emergiu a despeito de suas intenções e ações" (ELIAS, 1993, p. 140). As figurações podem até estar em constante modificação, porém, "a forma que a configuração toma não será determinada por planos deliberados ou pelas intenções de alguns de seus membros, nem por grupo deles, nem mesmo por todos eles em conjunto" (ELIAS, 1980, p. 180).

O conceito de interdependência, por sua vez, é inerente ao conceito de figuração, na medida em que o mesmo constitui um dos elementos presentes nas relações sociais que, vistas em seu conjunto, são o que Elias chama de figuração. As relações de interdependência entre os atores sociais são explicitadas pelo conjunto de relações que os mesmos tecem entre si, formando diferentes grupos sociais, cada qual com sua dinâmica específica (ELIAS, 1995, p. 177).

Assim, para Elias, o processo de civilização comporta diferentes relações de interdependência, as quais produzem as mais diversas figurações sociais, cujas alterações são

4 Segundo Elias, o autocontrole é o código social de conduta, gravado tão fortemente no indivíduo que se torna um elemento constituinte do próprio, agindo até quando o indivíduo se encontra sozinho. Reportando-se a Freud, Elias identifica esse elemento como superego, o qual acompanha constantemente as transformações sofridas pela estrutura social e pela própria estrutura de personalidade do indivíduo. Assim, a força adquirida em nossa sociedade pela instalação do superego no indivíduo e sua explicitação na forma de autocontrole "são reflexo de um desenvolvimento histórico particular, são resultado de um processo civilizador" (ELIAS, 1994, p. 189). 
resultado de outras relações de interdependência existentes em seu interior, fazendo que o processo de civilização não se realize de forma homogênea e retilínea.

Esse mesmo processo de civilização possui uma direção específica, porém essa direção não é perceptível para os próprios indivíduos que participam desse processo. Tal direção só se torna perceptível a posteriori, como resultado da utilização de um método de análise histórica e sociológica, no qual dados empíricos de uma dada figuração social são vistos - e analisados - tomando-se como referência um grande espaço temporal, ou seja, dentro de uma perspectiva de longa duração. Quando olhamos os processos de civilização, utilizando-se dessa perspectiva de longa duração, percebemos que as mudanças nos níveis de controle das emoções são, por um lado, resultados desses processos, mas, por outro lado, também se constituem em elementos propulsores dos mesmos.

Assim, o conceito de civilização significa, entre outras coisas, uma mudança no patamar de controle das emoções, no sentido de que o homem, e as sociedades por ele formadas caminham progressivamente, mas não inexoravelmente, para um controle, tanto mais rígido quanto menos explícito, de suas emoções, de onde, podemos afirmar que os processos de civilização se constituem, necessariamente, em processos educativos, no sentido do "educar-se" do homem para que o mesmo possa viver pacificamente em sociedade. Se assim entendemos, a conclusão a que chegamos é que, para Elias, o controle das emoções é fundamental para os processos de civilização das sociedades, em oposição clara e inequívoca, à ideia de barbárie (BRANDÃO, 2007, p. 220).

Se considerarmos a escola como uma das principais instituições das sociedades modernas, podemos afirmar que os processos de civilização não só estão presentes na escola mas, principalmente, é em seu seio, por meio dos processos educativos, com seus respectivos métodos pedagógicos (BRANDÃO, 2003, p. 94, 98), que as mais diferentes variáveis dos processos de civilização se internalizam, pouco a pouco, dia após dia, nos homens, no caso, em nossas crianças e jovens. Isso não significa dizer que Elias pensou nas possíveis relações entre os processos de civilização das sociedades ocidentais modernas e qualquer questão educacional. Não, muito ao contrário. Não encontraremos qualquer texto de Elias que trabalhe algum conceito por ele desenvolvido relacionando-o com qualquer questão educacional. Apesar de ter escrito sobre diferentes temas, o máximo (se é que poderíamos dizer dessa maneira) de aproximação que Elias fez em seus escritos com as questões "educacionais" foi abordar questões linguísticas (ELIAS, 1994a).

A ausência de escritos de Elias sobre questões educacionais não significa que não possamos afirmar que a questão do controle das emoções é tão importante para o sucesso dos processos educativos quanto para a própria teoria eliasiana dos processos de civilização. Essa centralidade se deve ao fato de que, como alemão de nascimento e de formação, Elias parte do conceito alemão de Bildung, entendido como sendo a educação do ser humano completo (integral, como um todo indivisível).

Quando resgatamos a atual questão da violência escolar, com suas mais diversas manifestações, somos obrigados a resgatar também a importância que Elias concede à questão do controle das emoções como elemento chave no combate a toda forma de violência em 
todos os âmbitos da vida social. Para Elias, o indivíduo não comete atos violentos porque pode ser punido (controle social, externo, ou seja, a sociogênese), e sabendo que pode ser punido internaliza em sua psiqué (o superego de Freud) a "proibição" de não ser violento (controle interno, individual, a psicogênese).

$\mathrm{Na}$ escola dos tempos atuais, não deveria ser diferente. Se é, o é porque os indivíduos que cometem atos de violência (sejam, alunos, pais, professores ou funcionários) de qualquer natureza, já enxergam (ainda que conscientemente não percebam) uma espécie de "rachadura", ainda que minúscula, no monopólio estatal do uso da violência física, ou, com as mesmas palavras que já usamos, já enxergam a possibilidade de não serem punidos (ou, pelo menos, não serem punidos adequada e proporcionalmente aos seus atos), caso venham a cometer qualquer tipo de violência. Assim, não se trata de coincidência o fato de que os acontecimentos de violência escolar aumentem de forma inversamente proporcional à explicitação clara e inequívoca do monopólio estatal do uso da violência física. Isto posto, trata-se da materialização de um dos aspectos da teoria dos processos de civilização de Norbert Elias, o que mostra a sua absoluta atualidade.

\section{CONSIDERAÇÕES FINAIS}

Para concluir este texto, queremos destacar que retomar ou reconhecer as dimensões passionais, pulsionais e emocionais em nós pode tornar-se um aspecto fundamental no nosso processo de formação, especialmente quando esta é pensada e praticada em um ambiente como a escola, especialmente com os casos e fatos violentos que aí se desenrolam. Diante disso, surge a pergunta: "reprimir as paixões, como sugerem os estoicos, cristãos e a maioria dos modernos, ou encará-las como elementos naturais e constitutivos do homem?" (LACERDA, 2013, p. 48).

Essa é uma discussão que talvez pudesse ser promovida no momento em que situações desafiadoras, como é o caso da violência, surgirem no ambiente escolar, visto que o estabelecimento de maneira antecipada de um conjunto de regras, com direitos e deveres, não parece estar surtindo o efeito esperado. Controlar as emoções, dosar bem as paixões e fazer bom uso de nossas pulsões é uma tarefa a ser colocada na ordem do dia de nossas condutas. É sermos virtuosos, como propõe Aristóteles. Segundo ele:

\footnotetext{
....a excelência ética [areté], a dosagem passional que define cada virtude é, em todos os casos, objeto de um difícil ajuste às circunstâncias. Requer-se, igualmente, "todo um trabalho" para tornar-se virtuoso. Não é o primeiro que aparece que sabe, em todas as ocasiões, equilibrar seu comportamento passional como convém. De onde vem a dificuldade? É que não há uma fórmula universal desse equilíbrio. E aquele que em cada caso e por sua conta consegue atingi-lo não pode basear-se em nenhuma medida que seria válida para todos os homens, todas as condições sociais, para os dois sexos, etc. Em suma, para harmonizar as paixões, não se deve contar com uma Lei moral: em nome da lei só pode reprimir (LEBRUN, 1987, p. 24. Grifos do autor).
} 
Tradicionalmente consideradas em estado de conflito com o mundo racional, as emoções sempre foram tratadas como algo negativo que nos constitui e, por isso, precisariam ser controladas, dominadas, reprimidas e até mesmo extirpadas. O discurso mais recorrente contra elas afirma que se quisermos estabelecer um conhecimento verdadeiro, uma política justa e uma vida ética feliz, deveremos dominar, reprimir e extirpar o que é contingencial em nós, em nome do que é necessário e universal. Assim pretendeu fazer Platão, Tomás de Aquino, Descartes, entre outros (LACERDA, 2013; KORICHI, 2000). Todavia, há outra possibilidade que aqui queremos sobrelevar: ao invés de desvalorizá-las poderíamos, talvez, colocá-las em diálogo com a razão. Desse modo pretenderam fazer Aristóteles e outros filósofos. Pensamos também que assim propuseram Freud e até mesmo Norbert Elias.

Para Elias, as emoções humanas são um processo que tanto recebemos inativamente no processo evolutivo, como aprendemos (adquirimos) no processo de socialização. Nesse sentido, o que nos faz humanos é a nossa capacidade de conhecer e ter consciência de usar os nossos componentes biológicos e comportamentais. Logo, essa capacidade de conhecer e ter consciência faz que as emoções inatas fiquem sujeitas às emoções adquiridas socialmente. Isto é o que conduz ao processo de controle das emoções e à sua tese fundamental, que é o processo civilizador (ELIAS, 2009).

Esse diálogo entre a razão e as paixões ou esse caráter interdependente entre a dimensão biológica e cultural das emoções humanas significaria a busca de um equilíbrio, de tal modo que não apenas compreenderíamos o homem de maneira mais integral, mas também o formaríamos, o educaríamos e ele agiria melhor em prol de uma vida civilizacional ética e virtuosa.

\footnotetext{
O homem virtuoso não deve procurar extirpar suas emoções, como se a virtude fosse uma ausência de emoções, uma apatheia, como queriam os estoicos, mas, ao contrário, tomando-as como elementos indispensáveis da vida humana, ele deve buscar sua justa medida, graças à qual a ação será adequada e verdadeira do ponto de vista moral ao mesmo tempo em que fica ancorada nas emoções e paixões do agente (ZINGANO, 2009, p. 143. Grifo do autor).
}

Portanto, denunciar e condenar as emoções, as paixões e as pulsões humanas como meras fontes de barbárie não é suficiente, nem para compreendê-las e muito menos para delas tirarmos algum proveito. É preciso bem considerá-las, como tem acontecido em vários campos do saber (ANSART, 1983; DAMÁSIO, 2000, 2011; LE BRETON, 2009; REZENDE \& COELHO, 2010; SOLOMON, 2015).

No caso específico da educação escolar, a partir de uma perspectiva histórica, que vem desde a aurora da modernidade, tem indicado um pouco caso em relação ao mundo das paixões ou das emoções. Parecendo em sintonia com a análise eliasiana, a pedagogia tradicional tem entre as suas características o controle das emoções, em que o professor se tornou o centro do processo de ensino e aprendizagem, isto é, o detentor dos saberes e, de certo modo, o dono da verdade. O poder a ele outorgado fazia que pudesse impor uma rigorosa disciplina, controlando, assim, o grupo de educandos. Estes, por seu lado, tinham que desenvolver também um rigoroso autocontrole, especialmente em situação de sala de 
aula. A finalidade desse movimento estava em submeter e subjugar qualquer indício de irracionalidade aos ditames da razão.

$\mathrm{Na}$ esteira da proposta de Elias, se consideramos que o aspecto mais importante da teoria dos processos de civilização e das práticas educativas delas decorrentes é a questão do nível de controle das emoções, manifestado em uma dada sociedade, enquanto elemento motriz do processo de civilização dessa mesma sociedade, talvez o que precisamos garantir é o reconhecimento das emoções e tomá-las não como um obstáculo, mas como uma força que está a serviço do homem, bastando apenas educá-las.

Nesse sentido, Aristóteles também pode nos ajudar e, assim, contribuir para uma formação humana mais plena, inclusive na educação que se realiza na sala de aula. A posição aristotélica sugere a possibilidade de encontrarmos uma medida, uma justa medida, em função e no meio das circunstâncias em que se produzem as nossas ações, assemelhando-se com a proposta freudiana, que vê no equilíbrio das pulsões um caminho para assegurarmos a existência da civilização. "Se a felicidade é o fim último de todas as nossas ações, as ações devem ser aperfeiçoadas pela razão, mas, no início, estão as emoções” (ZINGANO, 2009, p. 145).

Enfim, com as contribuições de Aristóteles, Freud e Elias, em permanente diálogo, estamos diante de um tema fundamental e nos parece que cumpre a nós retomá-lo ou reatualizá-lo, de forma que possa contribuir para pensarmos as relações humanas, os indivíduos, a sociedade e, principalmente, a educação contemporânea. Especialmente diante dos fatos violentos - preconceito, discriminação, agressões físicas e verbais etc. - que temos notícias ou presenciado na e a partir da escola, a nossa empreitada é nos exercitarmos na direção de um modo de vida pautado na moderação, na prudência e na temperança, isto é, em virtudes que garantam a experiência da felicidade, da tolerância e do respeito, em que os nossos estados afetivos (emoções, paixões e pulsões) e a nossa capacidade racional, cultural e de aprendizagem tornem-se interdependentes e em permanente diálogo.

\section{REFERÊNCIAS}

AMÂNDIO, Sofia Lay. O lugar social das emoções na investigação em ciências sociais: reflexão em torno de uma diligência em sociologia. Forum Sociológico, Lisboa, nº 11/12 (2. ${ }^{\text {a }}$ Série), 2004, p. 363-372.

ANSART, Pierre. La gestion des passions politiques. Lausanne: L'Age d'homme, 1983.

APEOESP. Apresentação da Pesquisa sobre Violência Escolar. Disponível em http:// googleshortener.com/juyVT0. Acesso: 8 nov. 2017.

ARISTÓTELES. Ética a Nicômaco. São Paulo: Nova Cultural, 1987 (Os Pensadores).

BOCCA, Francisco V.; CAROPRESO, Fátima. Agressividade e relacionamento social em Freud. In: CANDIOTTO, Cesar (org.). Ética: abordagens e perspectivas. Curitiba: Champagnat, 2011. 
CHAUÍ, Marilena. Convite à Filosofia. São Paulo: Ática, 2003.

. Introdução à História da Filosofia: dos pré-socráticos a Aristóteles. São Paulo: Cia. das Letras, 2011.

COSTA, André O.; ENDO, Paulo César. Corpo, transmissão e processo civilizador: Sigmund Freud e Norbert Elias. Trivium: Estudos interdisciplinares. Ano VI (edição II), 2014, p. 16-32. Disponível em http://googleshortener.com/0ugMd Acesso em 14 nov. 2017.

DAMÁSIO, António R. E o cérebro criou o homem. São Paulo: Cia. das Letras, 2011.

. O mistério da consciência. São Paulo: Cia. das Letras, 2000.

ELIAS, Norbert. A sociedade de corte, 2. ed. Lisboa: Editorial Estampa, 1995 (Nova História, 19) (Trad.: Ana Maria Alves).

ELIAS, Norbert. Introdução à sociologia. Lisboa: Edições 70, 1980 (Trad.: Maria Luísa Ribeiro Ferreira).

ELIAS, Norbert. O processo civilizador: uma história dos costumes, 2. ed. Rio de Janeiro: Jorge Zahar Editor, 1994, vol. 1 (Trad.: Ruy Jungmann).

ELIAS, Norbert. O processo civilizador: formação do Estado e civilização. Rio de Janeiro: Jorge Zahar Editor, 1993, vol. 2 (Trad.: Ruy Jungmann).

ELIAS, Norbert. Os alemães: a luta pelo poder e a evolução do habitus nos séculos XIX e XX. Rio de Janeiro: Jorge Zahar Editor, 1997 (Trad.: Álvaro Cabral).

ELIAS, Norbert. Sobre os seres humanos e suas emoções: um ensaio sob a perspectiva da sociologia dos processos. In: GEBARA, A.; WOUTERS, C. (Orgs.). O controle das emoções. João Pessoa: UFPB, 2009, 260p. Resenha de: ROCHA, Márcio José O. Educação e Fronteiras On-Line, Dourados/MS, v. 1, n. 2, p. 144-146, jan./abr. 2011.

FOLHA DE SÃO PAULO. SP tem quase 2 professores agredidos ao dia; ataque vai de soco a cadeirada. Disponível em http://googleshortener.com/vpWe. Acesso em 8 nov. 2017.

FREUD, Sigmund. Cinco lições de psicanálise. In: . Obras psicológicas completas de Sigmund Freud. Rio de Janeiro: Imago, 1996, v. XI.

. Moral sexual civilizada e doença nervosa moderna. In: . Obras psicoló-

gicas completas de Sigmund Freud. Rio de Janeiro: Imago, 1996, v. IX.

GOMES, Gilberto. Os dois conceitos freudianos de Trieb. Psicologia: Teoria e Pesquisa. Brasília, set./dez. 2001. Vol. 17, n. 3, p. 249-255.

KORICHI, Mériam. Les passions. Paris: Flammarion, 2000.

LACERDA, Tessa Moura. As paixões. São Paulo: Editora WMF Martins Fontes, 2013.

LE BRETON, David. As paixões ordinárias: antropologia das emoções. Petrópolis: Editora Vozes, 2009. 
LEBRUN, Gérard. O conceito de paixão. In: NOVAES, Adauto (org.). Os sentidos da paixão. São Paulo: Cia. das Letras, 1987.

LORDON, Fréderic. A sociedade do afetos: por um estruturalismo das paixões. Campinas: Papirus, 2015.

MARX, Karl. Manuscritos Econômico-Filosóficos. São Paulo: Boitempo, 2004.

MEYER, Michel. Aristóteles ou a retórica das paixões. In: ARISTÓTELES. Retórica das paixões. São Paulo: Martins Fontes, 2000.

OLIVEIRA, Fábio Sagula. A dinâmica das pulsões na escola: um diálogo entre psicanálise e educação. Marília: Unesp, 2016. Tese de Doutorado.

PEREIRA; SANTIAGO; LOPES. Apresentação do Dossiê Psicanálise e Educação. Marcelo Ricardo Pereira, Ana Lydia Bezerra Santiago e Elaine Marta Teixeira Lopes. Belo Horizonte, Educação em Revista, v. 25, n. 1, p. 139-148, 2009.

REZENDE, Cláudia B. \& COELHO, Maria Cláudia. Antropologia das emoções. Rio de Janeiro: Editora Fundação Getúlio Vargas, 2010.

SOLOMON, Robert C. Fiéis às nossas emoções: o que elas realmente nos dizem. Rio de Janeiro: Civilização Brasileira, 2015.

SOUZA, Jessé. Elias, Weber e a singularidade cultural brasileira. In: WAIZBORT, Leopoldo (org.). Dossiê Norbert Elias. São Paulo: Edusp, 1999, p. 63-88.

WEBER, Max. Economia e Sociedade: fundamentos da sociologia compreensiva. Brasília: Editora UnB, 1998 (vol. 1).

ZINGANO, Marco. Aristóteles: tratado da virtude moral. São Paulo: Odysseus Editora, 2008. . Estudos de ética antiga. São Paulo: Paulus; Discurso, 2009.

\section{DAdos dos AUTORES}

\section{Alonso Bezerra Carvalho Correio}

Professor do Departamento de Educação da Unesp/Assis e Programa de Pós-Graduação da Unesp/Marília. Doutor em Filosofia da Educação pela Faculdade de Educação da USP

\section{Carlos Fonseca Brandão Correio}

Professor do Departamento de Educação da Unesp/Assis e Programa de Pós-Graduação da Unesp/Marília. Doutor em Educação pela Unesp/Marília.

Submetido em: 17-8-2017

Aceito em: 17-11-2017 